\title{
KILAT
}

Vol. 10, No. 1, April 2021, P-ISSN 2089-1245, E-ISSN 2655-4925

DOI: https://doi.org/10.33322/kilat.v10i1.986

\section{Analisis RC Detector Sebagai Sensor Partial Discharge}

\author{
Andi Junaidi ${ }^{1}$; M. Imbarothur mowaviq ${ }^{2}$; Rudina Okvasari ${ }^{3}$ \\ 1, 2, 3 Institut Teknologi PLN \\ ${ }^{1}$ andi.junaidi@itpln.ac.id
}

\begin{abstract}
Partial Discharge is a localized electric discharge that only partially connects insulation between conductors, and can appear parallel or not to the conductor. Partial discharge (PD) has long been recognized as an important indication of the state of isolation in high voltage equipment. By measuring PD, a diagnosis of the degree of degradation or deterioration in the isolation conditions of a high voltage device can be determined. Partial Discharge that occurs continuously can cause damage (breakdown) on a high voltage equipment. Therefore, before a high voltage device is used, Partial Discharge detection is necessary. Partial Discharge Detection can use the Partial Discharge measurement circuit. In this study, one part of the Partial Discharge measurement series will be discussed, namely the RC detector. Hopefully, RC detector can be further developed and can be used for more accurate partial discharge detection.
\end{abstract}

Keywords: Partial Discharge, High Voltage, RC Detector

\begin{abstract}
ABSTRAK
Partial Discharge merupakan discharge elektrik terlokalisasi yang hanya secara sebagian menghubungkan insulasi diantara konduktor, dan dapat muncul sejajar atau tidak terhadap konduktor. Partial discharge (PD) telah lama dikenal sebagai salah satu indikasi penting keadaan isolasi pada peralatan tegangan tinggi. Dengan melakukan pengukuran PD, dapat ditentukan diagnosa terhadap tingkat degradasi atau penurunan kondisi isolasi dari suatu peralatan tegangan tinggi. Partial Discharge yang terjadi terus menerus dapat menyebabkan kerusakan (breakdown) pada suatu peralatan tegangan tinggi. Oleh karena itu, sebelum suatu perlatan tegangan tinggi digunakan, perlu adanya deteksi Partial Discharge. Deteksi Partial Discharge ini dapat menggunakan rangkaian pengukuran Partial Discharge. Pada penelitian ini, akan dibahas salah satu bagian dari rangkaian pengukuran Partial Discharge, yaitu RC detector. Dengan harapan, RC detector dapat dikembangkan lebih jauh dan dapat digunakan untuk deteksi partial discharge lebih akurat.
\end{abstract}

Kata kunci: Partial Discharge, Tegangan Tinggi, RC Detector 


\section{PENDAHULUAN}

Partial discharge (PD) telah lama dikenal sebagai salah satu indikasi penting keadaan isolasi pada peralatan tegangan tinggi. Dengan melakukan pengukuran PD, dapat ditentu kan diagnosa terhadap tingkat degradasi atau penurunan kondisi isolasi dari suatu peralatan tegangan tinggi [1].

Pengukuran PD dapat mengetahui kondisi isolasi sehingga dapat meningkatkan stabilitas sistem dan mengurangi kerugian secara ekonomidikarenakan peralatan yang rusak[2][3]. Pengukuran utama untuk pelepasan parsial peralatan listrik bertegangan tinggi dapat dibagi menjadi dua jenis: deteksi offline dan deteksi online [4]. Kebutuhan deteksi offline peralatan dimatikan sehingga aplikasi biasanya digunakan dalam pengujian dan pemeliharaan. Deteksi online tidak perlu dimatikan dan dapat menggunakan banyak sensor untuk mengukur PD. Oleh karena itu, deteksi online merupakan pengukuran yang direkomendasikan dalam beberapa tahun terakhir [5-7]. Partial Discharge yang terjadi terus menerus dapat menyebabkan kerusakan (breakdown) pada suatu peralatan tegangan tinggi. Oleh karena itu, sebelum suatu perlatan tegangan tinggi digunakan, perlu adanya deteksi Partial Discharge. Deteksi Partial Discharge ini dapat menggunakan rangkaian pengukuran Partial Discharge. Pada penelitian ini, akan dibahas salah satu bagian dari rangkaian pengukuran Partial Discharge, yaitu RC detector.

Peralatan tegangan tinggi secara umum terdiri atas dua bagian, yaitu bagian bertegangan tinggi dan isolasi. Akibat proses manufaktur, distribusi, instalasi, maupun operasi, maka pada bagian isolasi dapat timbul void berisi udara/gas. Void memiliki kuat tembus yang lebih rendah dibandingkan dengan isolasi. Oleh karena itu, pada keadaan tegangan tinggi yang seharusnya masih berada di bawah ambang batas kemampuan isolasi, dapat terjadi tembus elektrik lebih awal pada void [8]

Partial discharge (PD) terjadi ketika medan listrik pada void melebihi batas kuat tembus gas di dalamnya. Menurut standar internasional IEC 60270 tahun 2000, PD didefinisikan sebagai peluahan elektrik setempat yang hanya menghubungkan secara parsial isolasi antar konduktor dan dapat atau tidak dapat terjadi di dekat sebuah konduktor[9]. Secara umum, PD dapat dikatakan sebagai hasil konsentrasi stress elektrik lokal di dalam atau di permukaan isolasi[10].

\section{METODE/PERANCANGAN PENELITIAN}

\subsection{Metode UHF (Ultra High Frequency)}

Sampai saat ini, metode pengukuran arus impuls (biasa disebut metode konvensional) merupakan satu-satunya metode deteksi PD yang telah distandardisasi secara internasional di dalam IEC 60270. Sedangkan metode deteksi gelombang elektromagnetik dan akustik ke depan akan menyusul sebagai bagian dari IEC 62478.

Dalam eksperimen laboratorium partial discharge dapat dibuat dengan beberapa model partial discharge, model-model partial discharge berbeda tergantung jenis eksperimen partial discharge yang akan dilakukan. Berikut adalah tiga model umum :
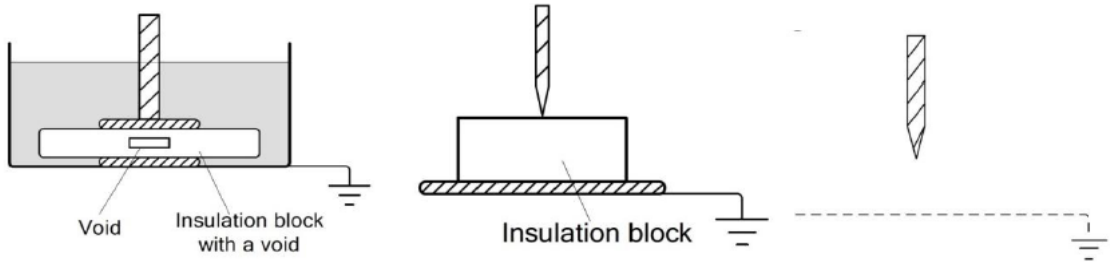

Gambar 1. Model pengujian partial discharge 


\section{KILAT}

Vol. 10, No. 1, April 2021, P-ISSN 2089-1245, E-ISSN 2655-4925

DOI: https://doi.org/10.33322/kilat.v10i1.986

RC Detector berfungsi untuk mengukur tegangan secara langsung berdasarkan munculnya arus bocor dari fenomena partial discharge RC detector ini I ni digunakan untuk mengonversi arus frekuensi tinggi yang telah dialirkan oleh kopling kapasitor menjadi tegangan

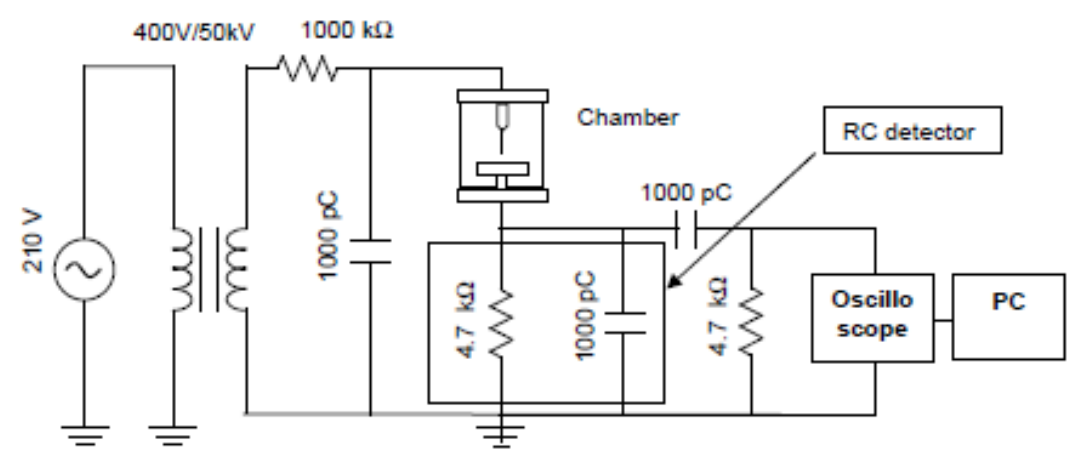

Gambar 2. Rangkaian pengujian partial discharge

Untuk keperluan penelitian ini, telah dibuat buah rangkaian RC detector dengan rincian sebagai berikut:

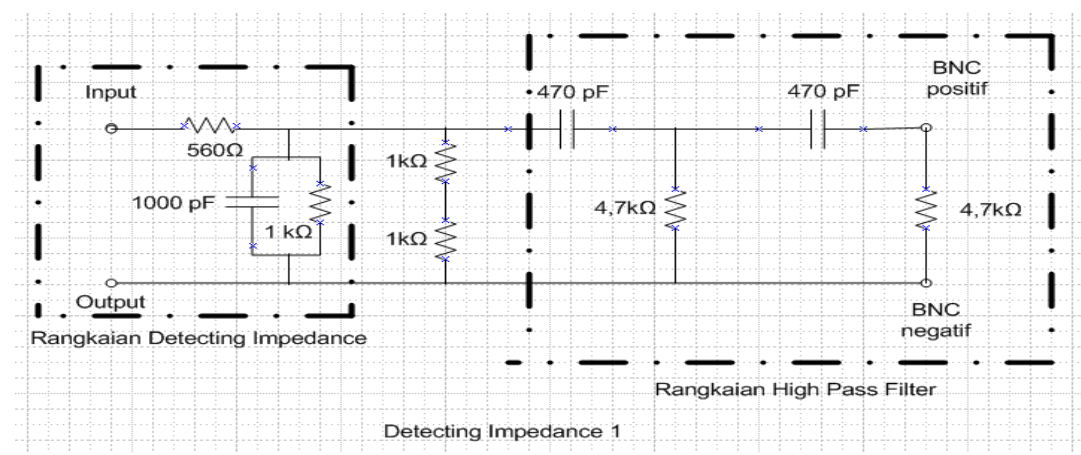

Gambar 3. Rangkaian RC Detector 1

Rangkaian detecting impedance 1 memiliki nilai resistansi $1000 \Omega$ dan kapasitansi 1000 Pf

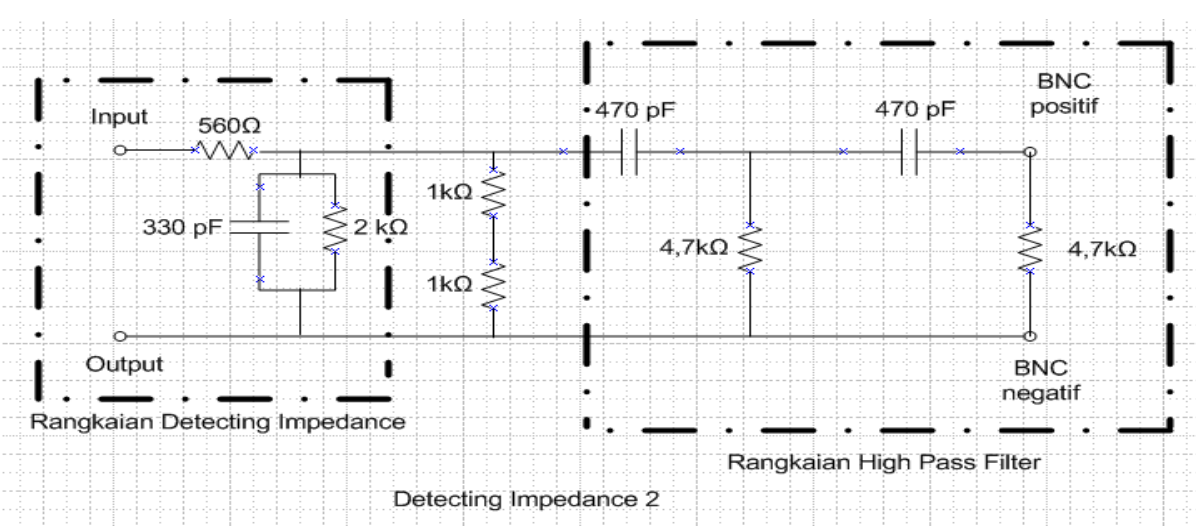

Gambar 4. Rangkaian RC Detector 2 


\section{HASIL DAN PEMBAHASAN}

\subsection{Hasil Pengujian HFCT}

Rangkaian pengujian partial discharge yang akan dilakukan pada rangkaian RC detector menggunakan beberapa komponen pengujian seperti trafo tegangan tinggi, regulator tegangan, elektroda jarum dengan gap $5 \mathrm{~mm}$, isolasi minyak ester, limiter resistor, capacitor divider, rangkaian RC detector, osiloskop, komputer yang dilengkapi dengan software freeewave, serta instrument ukur. Adapun jenis sensor lain yang akan dijadikan pembanding hasil pengukuran adalah sensor HFCT.

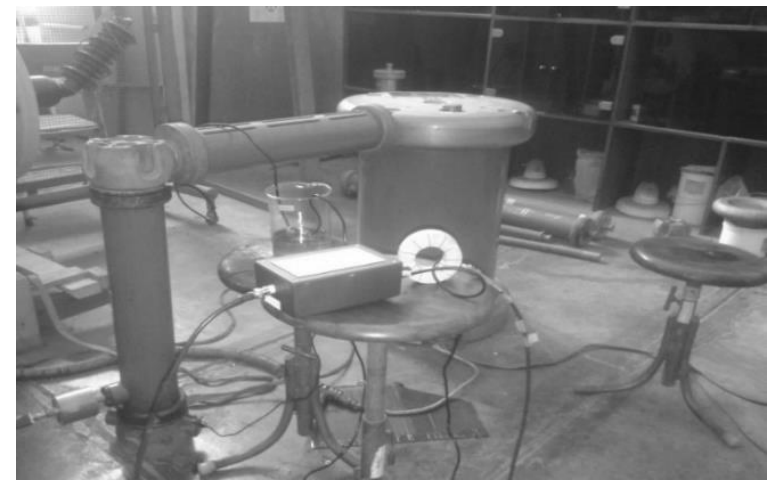

Gambar 5. Rangkaian pengujian partial discharge

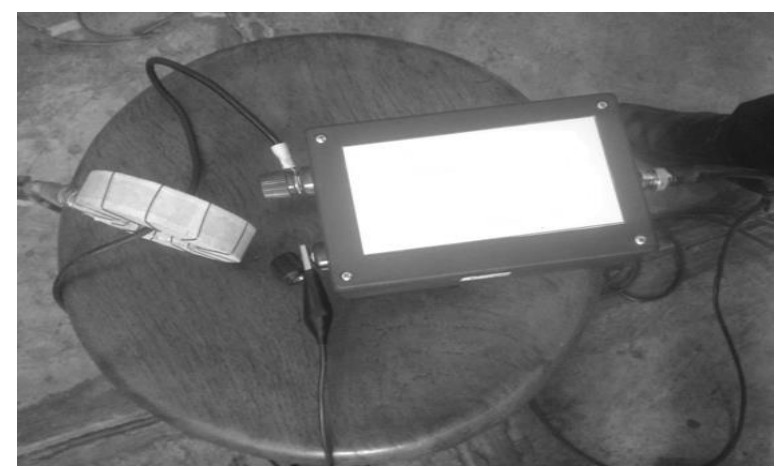

Gambar 6. Sensor HFCT sebagai pembanding hasil uji RC detector

\subsection{Pengujian RC Detector 1}

\subsubsection{Pengujian Background Noise}

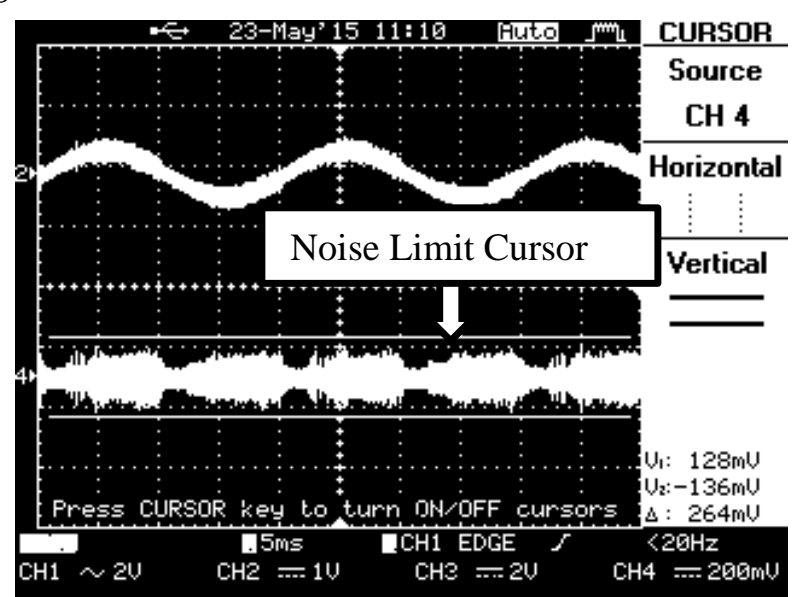

Gambar 7. Pengujian BGN on RC detector 1 


\section{KILAT}

Vol. 10, No. 1, April 2021, P-ISSN 2089-1245, E-ISSN 2655-4925

DOI: https://doi.org/10.33322/kilat.v10i1.986

Pengujian background noise hanya dilakukan dalam keadaan on, tetapi untuk keadaan off tidak dilakukan. Pengujian background noise dilakukan untuk menentukan batasan kursor pada osiloskop sehingga dapat membedakan hasil pengukuran noise dan partial discharge. Nilai tegangan dari maximum hingga minimum adalah $264 \mathrm{mV}$.

\subsubsection{Pengujian PDIV}

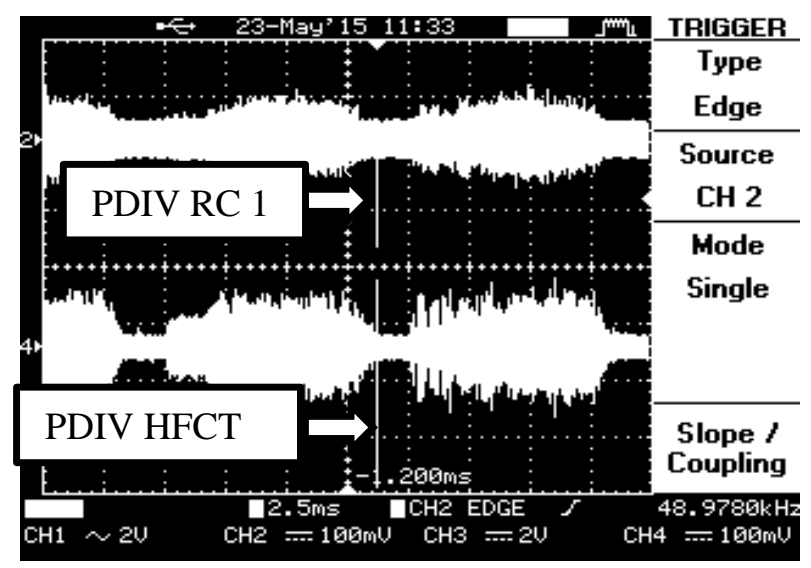

Gambar 8. Pengujian PDIV RC Detector 1

Pengujian PDIV ini dilakukan pada isolasi cair, yaitu minyak ester. Berdasarkan nilai peluahannya, isolasi cair minyak ester memiliki nilai isolasi yang cukup tinggi sehingga dibutuhkan tegangan yang cukup tinggi untuk membuat isolasi minyak mengalami partial discharge. Pengujian PDIV pada rangkaian RC detector 1 untuk mengetahui bagaimana respon pengukuran sesnor tersebut. berdasarkan data pengujian diatas dapat diketahui bahwa kedua sensor dapat mendeteksi adanya tegangan awal partial discharge dan mempunyai pola pengukuran yang hampir sama. PDIV pada rangkaian RC detector 1 pada isolasi minyak muncul pada nilai 3,45 x $4=13,8 \mathrm{kV}$.

\subsubsection{Pengujian 1,5xPDIV}

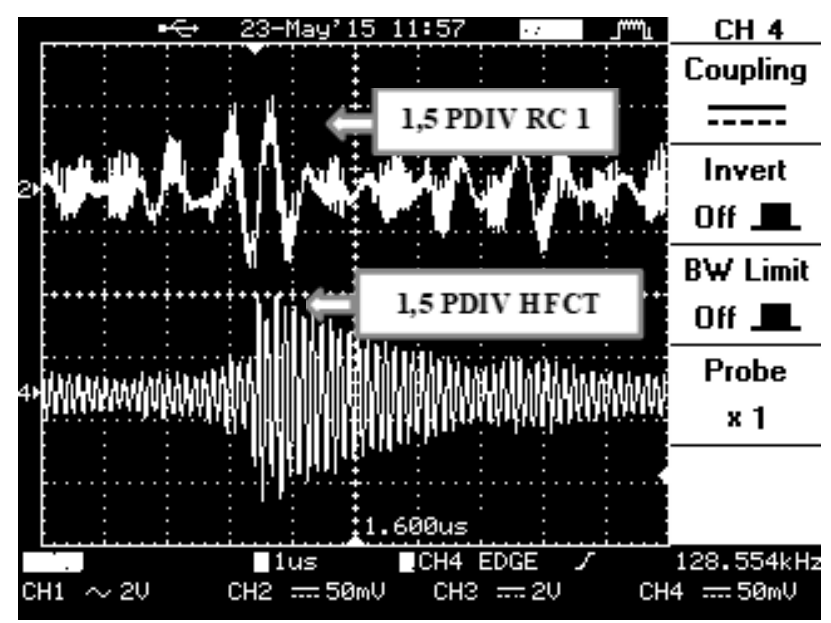

Gambar 9. Pengujian 1,5xPDIV RC Detector 1

Pengujian 1,5xPDIV ini dilakukan untuk mengetahui kekuatan isolasi cair sebelum mencapai tegangan breakdown. 1,5xPDIV pada rangkaian RC detector ditunjukkan oleh kurva berwarna 
kuning dan menunjukkan adanya partial discharge pada kurva puncak tegangan. Pengujian 1,5xPDIV pada rangkaian RC detector ini juga dibandingkan dengan sensor HFCT untuk mengetahui kesamaan bentuk gelombang kedua sensor tersebut. berdasarkan data pengujian diatas dapat diketahui bahwa kedua sensor dapat mendeteksi 1,5xPDIV dan mempunyai pola pengukuran yang hampir sama. Nilai 1,5xPDIV rangkaian RC detector pada isolasi minyak adalah 3,45 x 1,5 x 4=20,7 kV.

\subsection{Pengujian RC Detector 2}

\subsubsection{Pengujian $1,5 x P D I V$}

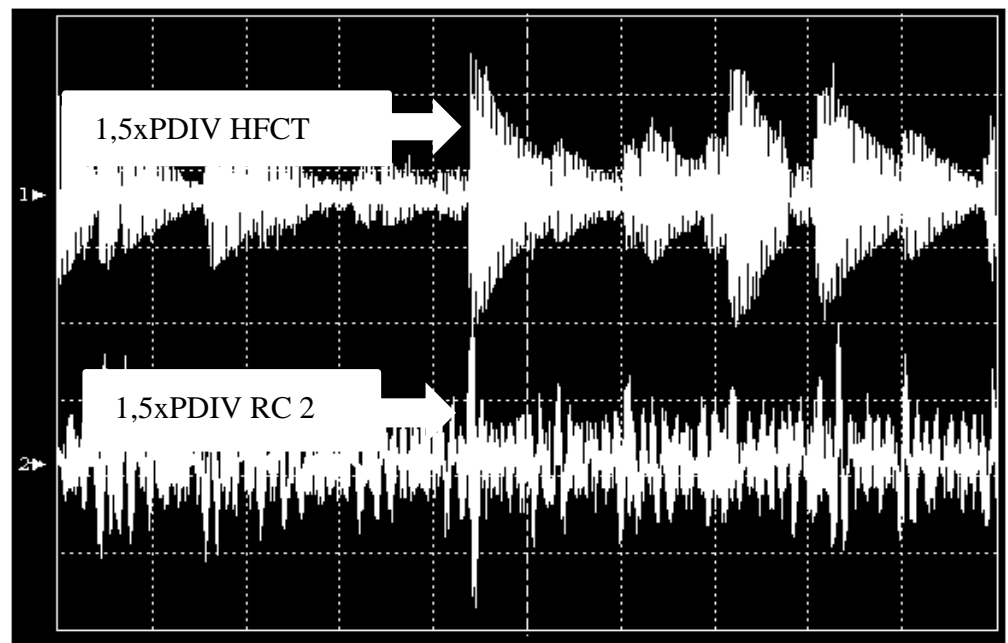

Gambar 10. Pengujian PDIV RC Detector 2

Pengujian 1,5xPDIV pada rangkaian RC Detector 2 ini masih menggunakan isolasi minyak sebagai objek uji. Pengujian 1,5xPDIV pada rangkaian RC detector 2 ini dibandingkan dengan sensor HFCT yang berbeda dengan rangkaian pengujian pertama untuk mengetahui bagaimana respon pengukuran kedua sensor tersebut. berdasarkan data pengujian diatas pengukuran RC detector 2 menghasilkan kurva deteksi partial discharge yang lebih banyak dibanding rangkaian RC detector 1. Nilai 1,5xPDIV pada rangkaian RC detector pada isolasi minyak muncul pada nilai 3,65 $\mathrm{x} 1,5 \mathrm{x} 4=21,9 \mathrm{kV}$.

\subsubsection{Pengenalan Pola Partial Discharge}

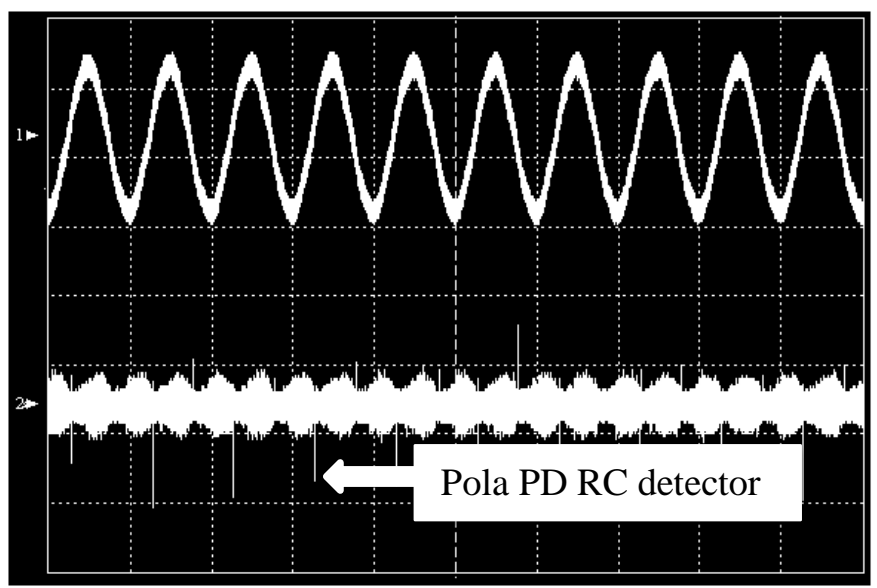

Gambar 11. Pengenalan pola fasa RC Detector 


\section{KILAT}

Vol. 10, No. 1, April 2021, P-ISSN 2089-1245, E-ISSN 2655-4925

DOI: https://doi.org/10.33322/kilat.v10i1.986

Pengukuran pola partial discharge pada rangkaian $\mathrm{RC}$ detector 2 memiliki bentuk yang hampir sama dengan pengujian rangkaian $\mathrm{RC}$ detector 1 , yaitu memiliki pola fasa negatif dan ditunjukkan dengan adanya puncak tegangan yang memiliki interval waktu yang sama pada sisi negatif. Hal ini cukup membuktikan bahwa rangkaian RC detector 2 dapat mendeteksi adanya partial discharge.

\subsection{Hasil Pengujian PD}

Tabel 1. hasil pengujian

\begin{tabular}{|c|c|c|c|c|}
\hline \multirow{2}{*}{ Pengujian } & \multicolumn{2}{|c|}{ RC detector 1 } & \multicolumn{2}{c|}{ RC detector 2} \\
\cline { 2 - 5 } & $\mathrm{V}$ & $\mathrm{kV}$ & $\mathrm{V}$ & $\mathrm{kV}$ \\
\hline BGN Off & - & - & - & - \\
\hline BGN On & 0,32 & - & - & - \\
\hline PDIV & 3,45 & 13,8 & - & - \\
\hline 1,5 PDIV & 5,175 & 20,7 & 5,4 & 21,9 \\
\hline 2 PDIV & - & - & - & - \\
\hline
\end{tabular}

\subsection{Pengujian Breakdown Voltage}

Tabel 2. Pengujian Breakdown Voltage

\begin{tabular}{|l|l|l|}
\hline \multirow{2}{*}{ Breakdown Voltage } & Multimeter ( V ) & Tegangan aktual $(\mathrm{kV})$ \\
\cline { 2 - 3 } & 4,58 & 27 \\
\hline
\end{tabular}

\subsection{Data ambient}

Tabel 3. Data Ambient

Data ambient

\begin{tabular}{|l|l|}
\hline Humidity $(\%)$ & Temperature $\left({ }^{\circ} \mathrm{C}\right)$ \\
\hline 62,8 & 28 \\
\hline
\end{tabular}

\section{KESIMPULAN DAN SARAN}

Rangkaian RC detector adalah sebuah alat yang dapat mengukur adanya kegiatan partial discharge. Melalui simulasi PSIM, dapat dibuktikan bahwa rangkaian RC detector dapat mengkonversi arus sumber pengukuran menjadi tegangan, sehingga kita dapat menggunakan kurva tegangan sebagai sumber pengukuran partial discharge. Adapun hasil penelitian di tegangan tinggi menunjukkan bahwa rangkaian RC telah berhasil mendeteksi adanya partial discharge dengan beberapa pengujian seperti PDIV, 1,5xPDIV, dan pengenalan pola fasa. Berdasarkan hasil pengujian tersebut dapat disimpulkan bahwa rangkaian RC detector yang telah direncanakan mampu mendeteksi adanya partial discharge.

\section{DAFTAR PUSTAKA}

[1] IEC Standard 60270, Partial Discharge Measurement, 2nd edition, 1981

[2] Kreuger, FH 1964, Partial Discharge Detection in High Voltage Equipment, American Elsevier, New York.

[3] IEEE 400.3 "Guide for PD Testing of Shielded Power Cable Systems in a Field Environment.". 
[4] E. Gulski, P. Cichecki, F. Wester, J. Smit, R. Bodega, T. Hermans, P. P. Seitz, B. Quak, and F. deVries, "On-site testing and PD diagnosis of high voltage power cables," IEEE Transactions on Dielectrics and Electrical Insulation, Vol. 15, No 6, pp. 1691-1700, Dec 2008.

[5] G. C. Stone, M. K. W. Stranges, and D. G. Dunn, "Common Questions on Partial Discharge Testing: A Review of Recent Developments in IEEE and IEC Standards for Offline and Online Testing of Motor and Generator Stator Windings" IEEE Industry Applications Magazine, Vol.22, No 1, pp. 14-19, Jan.-Feb. 2016.

[6] S. M. Gargari, P. A. A. F. Wouters, P. C. J. M. van der Wielen, and E. F. Steennis, "Partial discharge parameters to evaluate the insulation condition of on-line located defects in medium voltage cable networks" IEEE Transactions on Dielectrics and Electrical Insulation, Vol. 18, No 3, pp. 868-877, June 2011.

[7] I. Blokhintsec, C. L. Patterson, B. J. Cassidy, and A. H. Loesch"Advantage of on-line partial discharge continuous monitoring of medium voltage substation," 2009 IEEE Electrical Insulation Conference, Canada, June 2009

[8] Aulia, Suwarno. Comparison of RC Detector and HFCT for PD Measurement in Liquid Insulation. School of Electrical Engineering and Informatics, Institut Teknologi Bandung.

[9] Winarko Ari P., Abdul Syakur, Yuningtyastuti. Analisis Partial Discharge Pada Material Polimer Resin Epoksi Dengan Menggunakan Elektroda Jarum Bidang. Jurusan Teknik Elektro Fakultas Teknik Universitas Diponegoro Semarang.

[10] Hermawan, Abdul Syakur. The Analysis Of Partial Discharge (Pd) From Electrical Treeing In Linear Low Density Polyethylene (LLDPE) And High Density Polyethylene (HDPE). Jurusan Teknik Elektro Fakultas Teknik Universitas Diponegoro 